\title{
Stoichiometric homeostasis predicts plant species dominance, temporal stability, and responses to global change
}

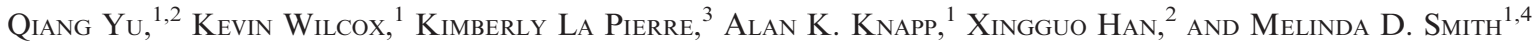 \\ ${ }^{1}$ Department of Biology and Graduate Degree Program in Ecology, Colorado State University, Fort Collins, Colorado 80523 USA \\ ${ }^{2}$ State Key Laboratory of Forest and Soil Ecology, Institute of Applied Ecology, Chinese Academy of Sciences, \\ Shenyang 110016 China \\ ${ }^{3}$ Department of Integrative Biology, University of California, Berkeley, California 94720 USA
}

\begin{abstract}
Why some species are consistently more abundant than others, and predicting how species will respond to global change, are fundamental questions in ecology. Long-term observations indicate that plant species with high stoichiometric homeostasis for nitrogen $\left(H_{\mathrm{N}}\right)$, i.e., the ability to decouple foliar $\mathrm{N}$ levels from variation in soil $\mathrm{N}$ availability, were more common and stable through time than low- $H_{\mathrm{N}}$ species in a central U.S. grassland. However, with nine years of nitrogen addition, species with high $H_{\mathrm{N}}$ decreased in abundance, while those with low $H_{\mathrm{N}}$ increased in abundance. In contrast, in climate change experiments simulating a range of forecast hydrologic changes, e.g., extreme drought (two years), increased rainfall variability (14 years), and chronic increases in rainfall (21 years), plant species with the highest $H_{\mathrm{N}}$ were least responsive to changes in soil water availability. These results suggest that $H_{\mathrm{N}}$ may be predictive of plant species success and stability, and how plant species and ecosystems will respond to global-change-driven alterations in resource availability.
\end{abstract}

Key words: climate change; climate extremes; drought; ecological stoichiometry; global change; Konza Prairie Biological Station, Kansas, USA; nitrogen deposition; tallgrass prairie; vascular plants.

\section{INTRODUCTION}

Stoichiometric homeostasis $(H)$ refers to the degree to which an organism maintains relatively constant elemental concentrations or ratios within its tissues when confronted with variation in the relative availabilities of elements in its environment or food supply (Elser et al. 2010). There are expected trade-offs between high vs. low $H$ for nutrients and growth or competitive ability. For example, vascular plant species with high $H$ tend to be slower growing but also capable of maintaining growth when resources are limiting, given the potential for greater conservative use of resources. In contrast, those species with low $H$ (and higher tissue concentrations of limiting nutrients) often are faster growing species that can take advantage of nutrients when they are plentiful (Lambers and Poorter 1992, Frost et al. 2005, Yu et al. 2012). The nutrient conservatism of high $H$-species could be an important mechanism contributing to their success, particularly in natural (unmodified) terrestrial ecosystems, where nutrient supply is often limiting and highly variable (Elser et al. 2010, Yu et al. 2010). Different plant tissues can have different $H$ values (Yu et al. 2011) but leaves, as the primary photosynthetic organs in most plant species, are the most

Manuscript received 4 October 2014; revised 16 January 2015; accepted 24 February 2015; final version received 1 April 2015. Corresponding Editor: S. K. Chapman.

${ }^{4}$ Corresponding author.

E-mail: Melinda.Smith@colostate.edu important plant tissues in terms of stoichiometry. In this case, if a plant species is able to maintain nutrient levels in its leaves, even when nutrient concentrations in the surrounding environment are suboptimal, it will likely be more successful at maintaining growth rates than those species more sensitive to nutrient availability. Thus, foliar $H$ is a trait that may be predictive of vascular plant species competitive success and abundance, including the potential to dominate communities subject to variability in resource supply (Jeyasingh et al. 2009, Yu et al. 2010, Sardans et al. 2012).

How vascular plant species abundance or degree of dominance is related to $H$ has been examined in two studies. In a long-term and spatially extensive study, plant species with high and temporally stable abundances had greater $H$ values for $\mathrm{N}\left(H_{\mathrm{N}}\right)$ and $\mathrm{N}: \mathrm{P}\left(H_{\mathrm{N}: \mathrm{P}}\right)$ in Inner Mongolia $\mathrm{C}_{3}$-dominated grasslands ( $\mathrm{Yu}$ et al. 2010). In contrast, in a short-term experiment, no general relationship was found between $H_{\mathrm{N}: \mathrm{P}}$ and species dominance in a $\mathrm{C}_{3}$ grassland in Wyoming, USA, although the most dominant species had the highest $H_{\mathrm{N}: \mathrm{P}}$ (Dijkstra et al. 2012). Thus, the role of $H$ in regulating species dominance and stability remains equivocal.

The trade-off between resource conservation in high$H$ species vs. fast-growth in low- $H$ species could be particularly important in predicting vascular plant species responses to increased $\mathrm{N}$ deposition, an important aspect of global environmental change. In this case, plant species that are successful with low $\mathrm{N}$ availability 
(i.e., high- $H_{\mathrm{N}}$ species) may be negatively impacted by increased $\mathrm{N}$ availability, due to their slow growth rate and the conservative use of resources associated with high $H_{\mathrm{N}}$ ( $\mathrm{Yu}$ et al. 2012), as well as the potential high energetic costs of maintaining a stable stoichiometry in these environments (Lambers and Poorter 1992, Sterner and Elser 2002). In contrast, plant species with low $H_{\mathrm{N}}$ would likely increase in abundance due to enhanced growth with higher $\mathrm{N}$ availability (Sardans et al. 2012). There is ample evidence that plant species respond differentially to nutrient addition (Xia and Wan 2008, Bai et al. 2010, Isbell et al. 2013, Borer et al. 2014), but how these differential responses may be related to $H_{\mathrm{N}}$ remains unknown.

Stoichiometric homeostasis also may be predictive of vascular plant species' responses to variation in other resources. Ecological stoichiometry reflects the net outcome of many underlying physiological and biochemical adjustments as organisms respond to their surroundings (Hessen et al. 2004). Thus, $H$ may more broadly encompass species strategies for coping with limiting soil resources in general (Sterner and Elser 2002), including water availability that can indirectly affect nutrient supply and uptake. As climate change is expected to alter soil water availability through a variety of mechanisms (increased variability in precipitation at short- and longer timescales, as well as chronic increases or decreases in this resource; e.g., Knapp et al. 2008, Smith et al. 2009), determining if species' responses to alterations in soil water are consistent with their $H$ for nutrients could more broadly inform predictions of plant species and ecosystem responses to global change.

We focus on three questions. First, is foliar $H$ predictive of plant species dominance and temporal stability in a $\mathrm{C}_{4}$-dominated grassland? Second, is foliar $H$ predictive of plant species responses to $\mathrm{N}$ addition? Third, is foliar $H$ predictive of responses of plant species to alterations in other limiting soil resources, such as water availability? To answer these questions, we estimated $H$ for foliar $\mathrm{N}\left(H_{\mathrm{N}}\right), \mathrm{P}\left(H_{\mathrm{P}}\right)$, and $\mathrm{N}: \mathrm{P}\left(H_{\mathrm{N}: \mathrm{P}}\right)$ of 11 vascular plant species in a native, North American tallgrass prairie ecosystem that is much more productive than the grasslands studies by $\mathrm{Yu}$ et al. (2010) and Dijkstra et al. (2012). We then examined relationships between foliar $H$ and species dominance and temporal stability using a 25-year data set, and the effects of $\mathrm{N}$ addition on the relationship between foliar $H$ and species dominance and species responses to chronic increases in $\mathrm{N}$ utilizing a long-term ( 9 year) $\mathrm{N}$-addition experiment. Finally, we examined the responses of three dominant species representing a twofold range of foliar $H$ values in three different climate change experiments that manipulated growing season precipitation (extreme drought, increased variability in precipitation, and increased precipitation inputs) to determine if foliar $H$ was predictive of species responses to alterations in water availability, another key limiting soil resource in tallgrass prairie ecosystems.

\section{Materials and Methods}

Five field experiments and a long-term (25-yr) plant species composition data set were utilized for this study (Appendix A: Table A1). The long-term data set was collected from, and all of the experiments were conducted at, the Konza Prairie Biological Station $\left(39^{\circ} 05^{\prime} \mathrm{N}, 96^{\circ} 35^{\prime} \mathrm{W}\right)$. Konza, which is located in northeastern Kansas, USA, experiences a midcontinental temperate climate with mean annual precipitation of $835 \mathrm{~mm}$ and average temperatures ranging from $-3^{\circ} \mathrm{C}$ in the winter to $27^{\circ} \mathrm{C}$ in the summer (Knapp et al. 1998). Grassland productivity at the site has been shown to be limited by both $\mathrm{N}$ and water availability (Blair 1997, Knapp et al. 1998, Avolio et al. 2014).

We calculated $H$ according to the model: $\log (y)=$ $\log (c)+\log (x) / H$, where $y$ is the foliar $\mathrm{N}$ or $\mathrm{P}$ concentration (\% dry mass) or N:P ratio of plants, $x$ is the inorganic $\mathrm{N}$ or available $\mathrm{P}$ concentration or $\mathrm{N}: \mathrm{P}$ ratio in the soil, and $c$ is a constant. Leaf tissue and soil samples for testing these models were collected in midJuly 2011 from two long-term nutrient addition experiments: the Phosphorus Plots experiment (PPlots, 20032011) and the Nutrient Network experiment at Konza (NutNet, 2008-2011). The PPlots experiment consists of $\mathrm{P}$ added at four levels $\left(0,2.5,5\right.$, and $10 \mathrm{~g} \cdot \mathrm{m}^{-2} \cdot \mathrm{yr}^{-2}$, respectively) and $\mathrm{N}$ added at two levels (0 and 10 $\mathrm{g} \cdot \mathrm{m}^{-2} \cdot \mathrm{yr}^{-1}$, respectively) crossed in a fully factorial design ( $n=6$ replicates per treatment combination). The NutNet experiment consists of $\mathrm{N}$ and $\mathrm{P}$ addition treatments at two levels $\left(0\right.$ and $10 \mathrm{~g} \cdot \mathrm{m}^{-2} \cdot \mathrm{yr}^{-1}$ each $)$ crossed in a fully factorial design $(n=3$ replicates per treatment combination; Borer et al. 2014). For each of the 11 vascular plant species that represented a range of relative abundances and two key functional groups (grasses and forbs; Table 1), the youngest, fully emerged, and expanded leaves (1-3 depending on leaf size) were clipped from each of 20-30 mature, phenologically similar individuals. These sampled leaves were pooled, ground, and mixed evenly for each species within each plot to be analyzed for total N (Bremner 1996) and P concentrations (Kuo 1996). Additionally, three random soil samples were taken at a depth of $0-10$ $\mathrm{cm}$ from each plot, pooled, ground, and mixed evenly for analysis of inorganic $\mathrm{N}$ (using a $1 \mathrm{~mol} / \mathrm{L} \mathrm{KCl}$ extraction; Wang et al. 2006) and Mehlich-3 extractable P concentration (Mehlich 1984).

To examine relationships between $H$ and species relative abundances (dominance) and temporal stability in abundance, we utilized 25 years of plant community composition data collected as part of the Long Term Ecological Research (LTER; 1983-2007) program at Konza (Appendix A: Table A1). Plant species cover was estimated using a modified Daubenmire method (Daubenmire 1952, Bailey and Poulton 1968) two times per year (late June and late July) within $10-\mathrm{m}^{2}$ circular plots each year. For each watershed, there were five $10 \mathrm{~m}^{2}$ plots $/ 50 \mathrm{~m}$ transect, with four transects per topographic position (upland and lowland), for a total of 40 plots (or 
TABLE 1. Log-linear regression model statistics and stoichiometric homeostasis coefficients (Coeff.) for nitrogen $\left(H_{\mathrm{N}}\right.$, with lower and upper 95\% confidence intervals) for 11 tallgrass prairie vascular plant species.

\begin{tabular}{lcccccc}
\hline \hline & & \multicolumn{5}{c}{$H_{\mathrm{N}}$} \\
\cline { 3 - 5 } \multicolumn{1}{c}{ Species } & & Lower & Upper & & \\
& Type & Coeff. & $95 \%$ & $95 \%$ & $R^{2}$ & $P$ \\
\hline Andropogon gerardii & $\mathrm{G}$ & 9.76 & 7.30 & 14.84 & 0.37 & $<0.001$ \\
Schizachyrium scoparium & $\mathrm{G}$ & 8.41 & 6.29 & 12.67 & 0.53 & $<0.001$ \\
Aster ericoides & $\mathrm{F}$ & 6.81 & 5.18 & 9.96 & 0.58 & $<0.001$ \\
Sorghastrum nutans & $\mathrm{G}$ & 6.75 & 5.65 & 8.40 & 0.64 & $<0.001$ \\
Salvia azurea & $\mathrm{F}$ & 6.63 & 4.44 & 13.00 & 0.44 & $<0.001$ \\
Solidago missouriensis & $\mathrm{F}$ & 6.28 & 4.59 & 9.98 & 0.48 & $<0.001$ \\
Dichanthelium oligosanthes & $\mathrm{G}$ & 5.53 & 4.12 & 8.40 & 0.52 & $<0.001$ \\
Bouteloua curtipendula & $\mathrm{G}$ & 5.49 & 4.55 & 6.94 & 0.75 & $<0.001$ \\
Ambrosia psilostachya & $\mathrm{F}$ & 5.34 & 3.73 & 9.35 & 0.47 & $<0.001$ \\
Solidago canadensis & $\mathrm{F}$ & 5.31 & 3.66 & 9.62 & 0.44 & $<0.001$ \\
Carex meadii & $\mathrm{S}$ & 4.45 & 3.66 & 5.68 & 0.73 & $<0.001$ \\
\hline
\end{tabular}

Note: Abbreviations are G, grass; $\mathrm{S}$, sedge; and F, forb (all other herbaceous species).

20 plots if only one topographic position was available). Species dominance was calculated as the mean relative cover (individual species cover/total plot cover) of a species averaged across all years and all plots. Species temporal stability was calculated as the mean relative cover of a species divided by its standard deviation across years (Tilman et al. 2006). To explore species responses to nutrient addition, species abundance (percent cover) data was collected from the ambient and $\mathrm{N}$ addition treatments of PPlots and NutNet experiment. These data were collected in either four $0.5 \times 0.5 \mathrm{~m}$ quadrats (PPlots) or one $1 \times 1 \mathrm{~m}$ quadrat (NutNut) located within in plot each year of the study (see Avolio et al. 2014, Borer et al. 2014 for details).

Responses of species that differed substantially ( $\sim$ twofold) in $H_{\mathrm{N}}$ values (Andropogon gerardii, Sorghastrum nutans, and Solidago canadensis; Table 1) were assessed in three climate change experiments that altered precipitation inputs: the climate extremes experiment (CEE; 2010-2011), Rainfall Manipulation Plots (RaMPs) experiment (1998-2011; see Plate 1), and the Irrigation Transect experiment (IrrT; 1991-2011). In addition to their differences in $H_{\mathrm{N}}$, these three species were selected because they were present in all three climate change experiments. For the CEE, ambient precipitation was reduced by $66 \%$ in two $105 \mathrm{~m}^{2}(5 \times 21$ m) tracts of lowland prairie from April to September of 2010 and 2011. Precipitation reductions occurred via roofs composed of evenly spaced clear corrugated polycarbonate strips that deflected a constant proportion of each precipitation event away from the plots below (Hoover et al. 2014). The RaMPs experiment was designed to evaluate the effects of increased rainfall variability on tallgrass prairie $(n=6$ replicates per precipitation treatment). For the altered precipitation treatment, the time between rainfall events was increased by $50 \%$ relative to the ambient rainfall treatment, without changing total rainfall amount (Fay et al. 2000). The IrrT experiment has increased precipitation by $\sim 37 \%$ each year to eliminate water limitation (Knapp et al. 2012). Three treatment transects (all $4 \mathrm{~m}$ wide, but transects vary in length: 50,100 , and $150 \mathrm{~m}$ long) receive supplementary irrigation events in addition to ambient precipitation and three control transects receive ambient precipitation (Knapp et al. 2001). Using the same methods as described previously, leaf tissue from the three focal species and soils were sampled in mid-July 2011.

Responses of A. gerardii, S. nutans, and S. canadensis to each of the precipitation manipulation treatments were determined by calculating response ratios using the equation

$$
\mathrm{RR}=\left|\ln \left(\frac{x_{\mathrm{m}}}{\bar{x}_{\mathrm{c}}}\right)\right|
$$

where $\bar{x}_{\mathrm{c}}$ represents mean relative cover of the control group and $x_{\mathrm{m}}$ represents the relative cover of the precipitation manipulation group within the corresponding experiment. Response ratios and species relative cover responses were compared in CEE using a nested mixed-effects model ANOVA and in IrrT and RaMPs using repeated-measures ANOVA in SAS (version 9.3; SAS Institute, Cary, North Carolina, USA). The effects of chronic nitrogen additions species dominance were also tested by repeated-measures ANOVA. Cover values of adjacent plots in the IrrT were pooled and averaged to make the data comply with normality requirements. There were four replicates in 1991 and 1992 and nine replicates from 1993 onward.

Species dominance and stability were compared with $H$ coefficients for $\mathrm{N}\left(H_{\mathrm{N}}\right), \mathrm{P}\left(H_{\mathrm{P}}\right)$, and $\mathrm{N}: \mathrm{P}\left(H_{\mathrm{N}: \mathrm{P}}\right)$ via both linear and nonlinear regression models, and models were selected based on best fit parameters. All the regressions were tested for and complied with assumptions of normality using quantile-quantile and residual plots using R (version 2.15.0; R Development Core Team 2012).

\section{RESUlts}

Relationships between leaf $\mathrm{N}$ concentration and soil inorganic $\mathrm{N}$, leaf $\mathrm{P}$ concentration, and soil plant- 


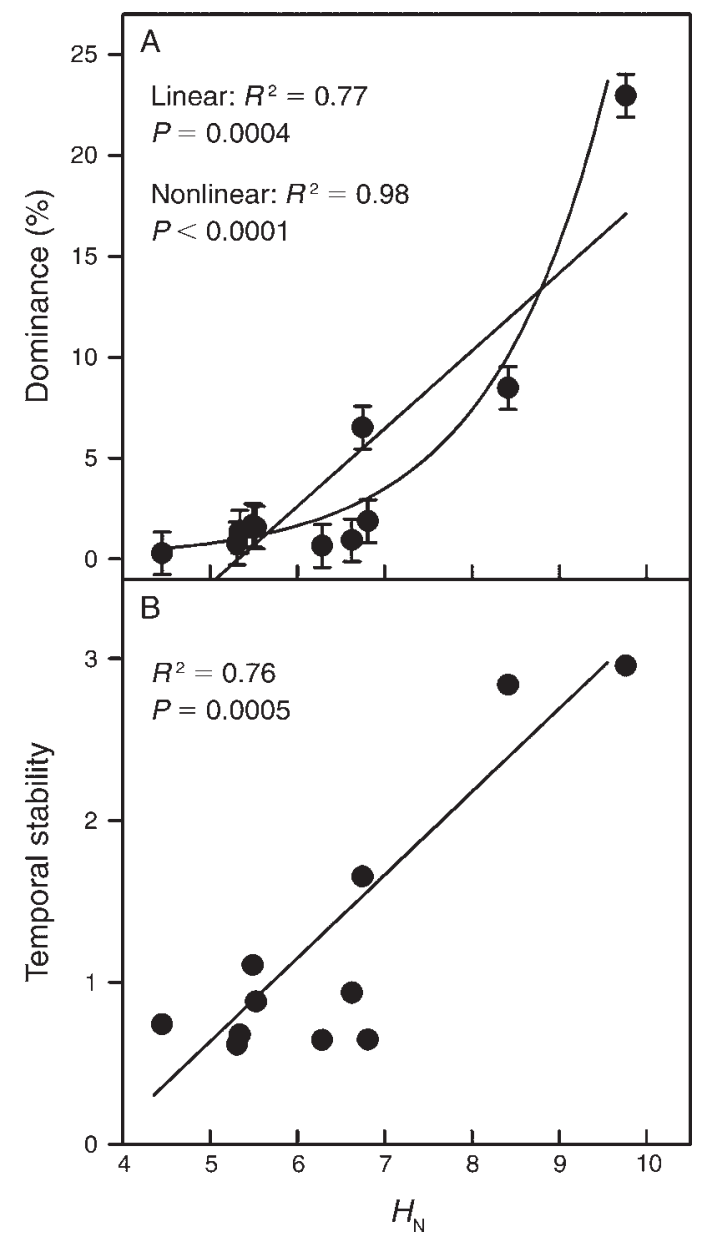

FIG. 1. Relationships between $H_{\mathrm{N}}$ and (A) species dominance (error bars are $\pm \mathrm{SE}$ ) and (B) temporal stability based on long-term (1983-2007) species composition data collected from intact tallgrass prairie. Species dominance was calculated as the mean relative cover, temporal stability was calculated as the mean relative cover of a species divided by its standard deviation across years, and $H_{\mathrm{N}}$ was calculated according to the model $\log (y)=\log (c)+\log (x) / H_{\mathrm{N}}$.

available $\mathrm{P}$, and leaf and soil $\mathrm{N}: \mathrm{P}$ ratios for 11 tallgrass vascular plant species were well-represented (in all but one case) by the model: $\log (y)=\log (c)+\log (x) / H$ (see Table 1). On average, this model explained $54 \% \pm 12 \%$ (mean $\pm \mathrm{SD}$ ) of the variation in leaf $\mathrm{N}$ concentration, $57 \% \pm 16 \%$ of the variation in leaf $\mathrm{P}$ concentration, and $67 \% \pm 14 \%$ of leaf N:P. Stoichiometric homeostasis coefficients for $\mathrm{N}\left(H_{\mathrm{N}}\right)$ for the 11 species evaluated ranged from 4.45 to 9.76 (Table 1 ), whereas $\mathrm{P}\left(H_{\mathrm{P}}\right)$ ranged from 3.14 to 9.60 and $\mathrm{N}: \mathrm{P}\left(H_{\mathrm{N}: \mathrm{P}}\right)$ ranged from 3.21 to 7.48 (Appendix B: Table B1). $H_{\mathrm{N}}$ values were not significantly correlated with $H_{\mathrm{P}}$ or $H_{\mathrm{N}: \mathrm{P}}$ values across the 11 species studied here $(P>0.05)$, although $H_{\mathrm{P}}$ and $H_{\mathrm{N}: \mathrm{P}}$ values were highly correlated $\left(R^{2}=0.90, P<\right.$ 0.001). Species with high $H$ tended to have lower foliar nutrient concentrations (Appendix C: Fig. C1). Relationships between $H$ (both $H_{\mathrm{N}}$ and $H_{\mathrm{P}}$ ) and foliar $\mathrm{N}$ concentrations were not significant across the 11 species studied, but when statistical outliers were removed, these relationships were significant $(P<0.10$; Appendix $\mathrm{C}$ : Fig. C1) indicating a link between foliar $H$ and nutrient concentrations.

Foliar $H_{\mathrm{N}}$ was significantly and positively correlated with plant species dominance (represented by mean relative cover) and temporal stability (Fig. 1). Foliar $H_{\mathrm{N}}$ explained $77 \%$ of the variation in dominance of both grass and forb species (a nonlinear relationship explained $98 \%$ of variation) and $76 \%$ of their temporal stability over a 25 -year period. In contrast to $H_{\mathrm{N}}$, no significant relationships were found between foliar $H_{\mathrm{P}}$, $H_{\mathrm{N}: \mathrm{P}}$, and species dominance and stability (Appendix B: Table B2). As a consequence, we focused on relationships between $H_{\mathrm{N}}$ and species responses to alterations in $\mathrm{N}$ and water availability.

During the first four years of the PPlots experiment, we found that foliar $H_{\mathrm{N}}$ and species dominance were

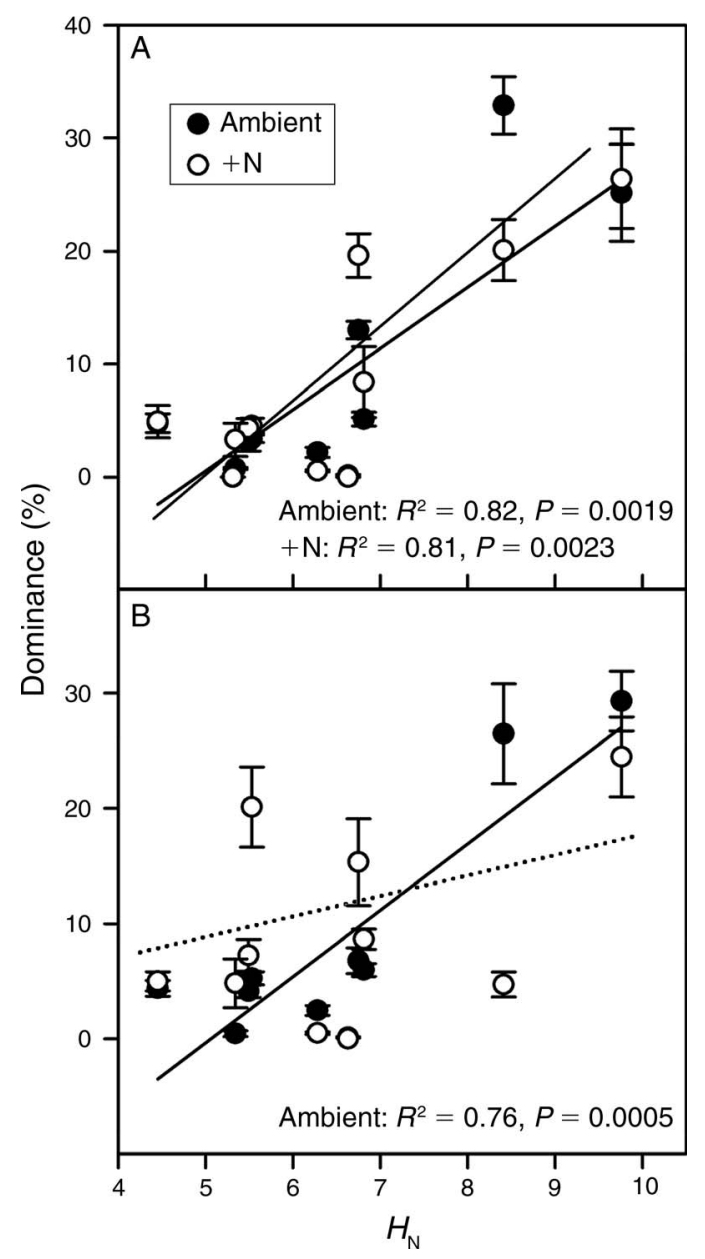

FIG. 2. Effects of chronic nitrogen additions on relationships between $H_{\mathrm{N}}$ and species dominance for (A) the first four years of $\mathrm{N}$ addition (2003-2006) and (B) the last five years of $\mathrm{N}$ addition (2007-2012). Error bars are \pm SE. See Methods for details. 


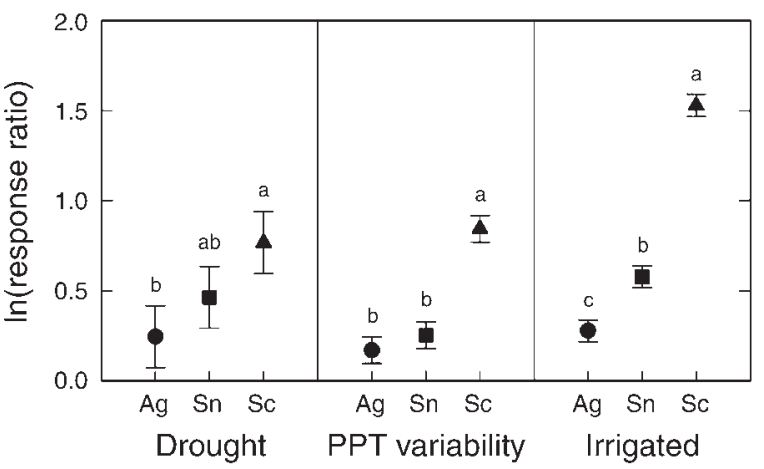

FIG. 3. Responses $(\ln (\mathrm{RR})$; see Materials and methods $)$ of Andropogon gerardii (Ag), Sorghastrum nutans (Sn), and Solidago canadensis $(\mathrm{Sc})$ to two years of extreme drought, 18 years of more variable rainfall regimes (PPT variability), and 19 years of irrigation. Data represent treatment means $\pm \mathrm{SE}$ and different letters denote significant differences $(\alpha=0.05)$. The $H_{\mathrm{N}}$ values for $\mathrm{Ag}, \mathrm{Sn}$, and $\mathrm{Sc}$ are 9.76, 6.75, and 5.31, respectively.

positively related for both the ambient and $\mathrm{N}$-addition treatments (Fig. 2A), with the slopes of these relationships not differing significantly $(P=0.60)$. A similar pattern was found for the NutNet experiment (data not shown, with slopes not significantly different, $P=0.68$ ). However, the positive relationship weakened after the fifth year of $\mathrm{N}$ addition for the PPlots experiment $(P=$ 0.15; Fig. 2B) with the slope decreasing from 5.8 to 2.2. The relative cover of all grass species combined was significantly affected by long-term $\mathrm{N}$ additions (repeated measures ANOVA, $P<0.05$ ). Dominance of the $\mathrm{C}_{4}$ grass with second highest $H_{\mathrm{N}}$ value, Schizachyrium scoparium, decreased significantly with $\mathrm{N}$ addition $(P<$ 0.001). Abundance of the $\mathrm{C}_{4}$ grass species with the highest $H_{\mathrm{N}}$ value (A. gerardii) also was reduced but not significantly. In contrast, other grass species, one $\mathrm{C}_{4}(S$. nutans; $P=0.007$ ) and one $C_{3}$ (Dichanthelium oligosanthes; $P<0.001)$ with lower $H_{\mathrm{N}}$ values significantly increased in abundance (Appendix B: Table B3). There were no significant responses for forbs, except for Ambrosia psilostachya, which increased significantly with $\mathrm{N}$ addition $(P<0.001$; Appendix B: Table B3).

We then examined responses of three species, which encompassed a $\sim$ twofold range of $H_{\mathrm{N}}$ values and also were differentially responsive to long-term alterations in $\mathrm{N}$ availability and to alterations in water availability designed to simulate forecast climate changes. Water availability was altered within three experiments, two years of extreme drought (2010-2011), 14 years of altered precipitation variability (1998-2011), and 21 years of irrigation (1991-2011). We found that the species with the highest $H_{\mathrm{N}}(A$. gerardii) responded the least (were most stable) to either reductions or increases in soil water availability, while the species with the lowest $H_{\mathrm{N}}$ (S. canadensis) was more responsive (Fig. 3). Moreover, the relationship between species dominance and $H_{\mathrm{N}}$ was not altered, i.e., the species with the highest $H_{\mathrm{N}}, A$. gerardii, remained the most abundant, while the species with the lowest $H_{\mathrm{N}}, S$. canadensis, was the least dominant in all the three experiments (Appendix D: Fig. D1). In addition, we found that changes in water availability did not alter the previously determined stoichiometric relationship between soil and foliar $\mathrm{N}$ concentration. For all three species, this relationship accurately predicted foliar $\mathrm{N}$ concentrations in all three experiments (predicted vs. actual leaf $\mathrm{N}$ values: slope $=$ $0.94, R^{2}=0.96, P<0.0001$; Appendix E: Fig. E1), and the slope did not significantly differ from $1(P=0.35)$.

\section{Discussion}

In this study, foliar $H_{\mathrm{N}}$ was significantly and positively correlated with plant species dominance and temporal stability over a 25 -year period in a highly productive, central U.S. $\mathrm{C}_{4}$-dominated grassland. These results correspond well with patterns in Inner Mongolian grassland $\left(\mathrm{a}_{3}\right.$-dominated grassland with lower productivity) in which foliar $H_{\mathrm{N}}$ was positively correlated with both species dominance and stability ( $\mathrm{Yu}$ et al. 2010). In contrast to $H_{\mathrm{N}}$, no significant relationships were found between foliar $H_{\mathrm{P}}, H_{\mathrm{N}: \mathrm{P}}$, and species dominance and stability. Consistent with these results, no relationship between $H_{\mathrm{N}: \mathrm{P}}$ and dominance was found in another North American $\mathrm{C}_{3}$-dominated grassland (Dijkstra et al. 2012) in the five species evaluated. Similarly, no relationship was detected between $H_{\mathrm{P}}$, $H_{\mathrm{N}: \mathrm{P}}$, and species dominance and stability in a shortterm experiment in an Inner Mongolia grassland ( $\mathrm{Yu}$ et al. 2010). At short timescales, these results suggest that $\mathrm{N}$ availability may be a more important driver of ecosystem function than $\mathrm{P}$ in these ecosystems. However, relationships between $H_{\mathrm{P}}$ and species dominance and stability were significant in the long-term studies in Inner Mongolia grasslands (Yu et al. 2010), which indicates that $\mathrm{P}$ also can become an important factor over more extended timescales in ecosystems that are co-limited by $\mathrm{N}$ and $\mathrm{P}$ (Elser et al. 2007). These results suggest that plant strategies for coping with a variable, limiting nutrient supply may provide more insight for predicting species success and how they will respond to global change. This may be particularly true in systems that are primarily $\mathrm{N}$-limited, such as tallgrass prairie ecosystem (Blair 1997, Knapp et al. 1998, Avolio et al. 2014).

The mechanisms underlying the relationship between $H_{\mathrm{N}}$ and species dominance and stability are likely a product of multiple physiological and biochemical processes (Hessen et al. 2004). Plants with higher $H_{\mathrm{N}}$ have been shown to be more conservative nutrient users (lower $\mathrm{N}$ concentrations) than plants with lower $H_{\mathrm{N}}(\mathrm{Yu}$ et al. 2011), as evidenced by significantly lower mean foliar nutrient concentrations for species with high $H_{\mathrm{N}}$ (and $H_{\mathrm{P}}$ ) values (Appendix C: Fig. C1). This suggests that conservative nutrient use may be critical for species success in infertile environments (Yu et al. 2010). In this and previous studies, the species with the highest $H_{\mathrm{N}}$ were consistently perennial grasses with well-developed storage systems (i.e., rhizomes), high root: shoot ratios 


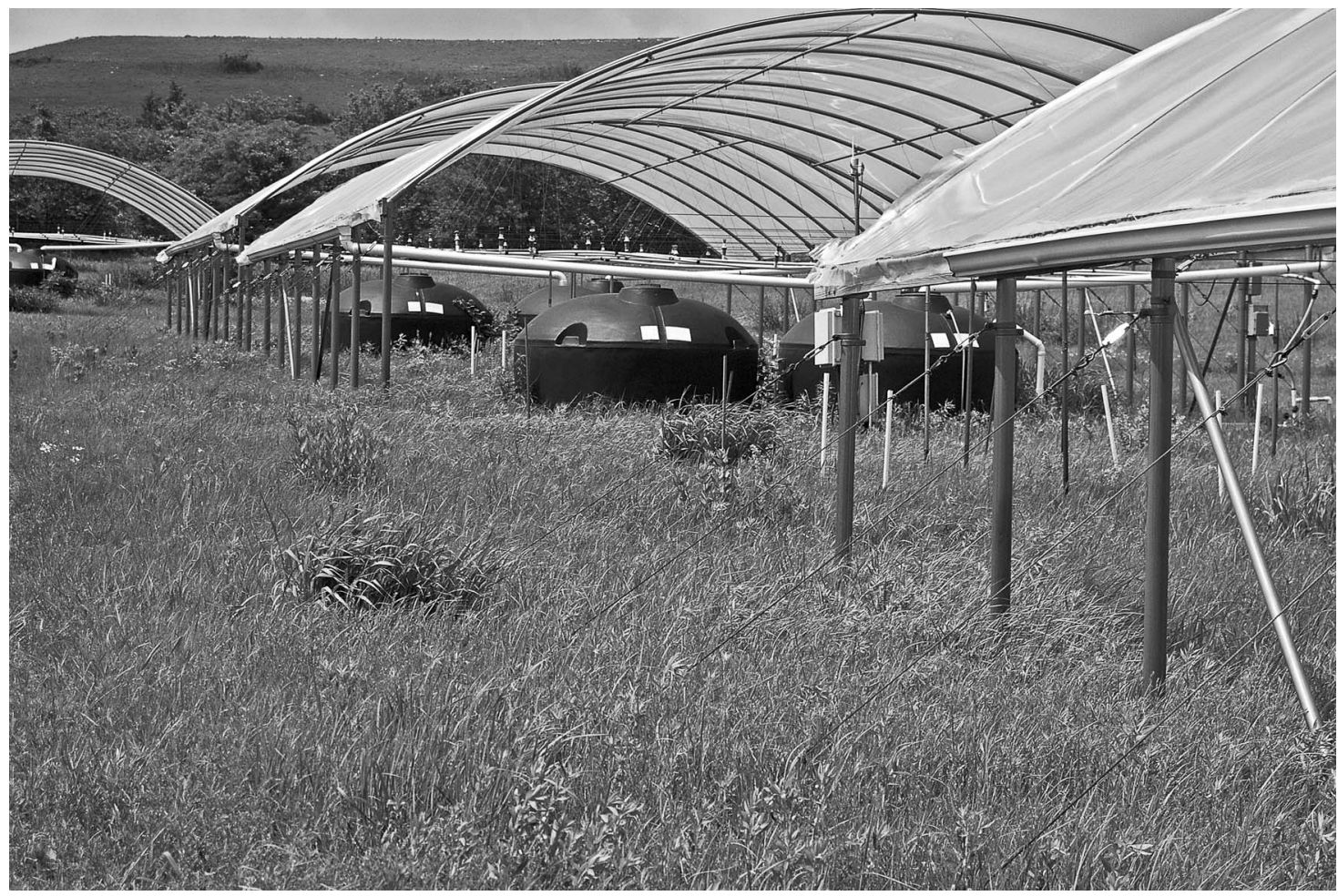

Plate 1. View of the Rainfall Manipulation Plots (RaMPs) experiment, initiated in 1998 at the Konza Prairie Biological Station, Kansas, USA. The RaMPs experiment was designed to evaluate the effects of altered rainfall patterns, as predicted by climate models, on the structure and function of a native mesic grassland (North American tallgrass prairie). Experimental plots are exposed to either (1) ambient rainfall patterns and amount during the growing season, or (2) ambient amounts of rain, but with the pattern altered so that the grassland experiences fewer but larger rain events with longer dry periods between them (See Fay et al. 2000 for additional details). Photo credit: A. K. Knapp.

(Johnson et al. 2008, Yu et al. 2010) and relatively low growth rates ( $\mathrm{Yu}$ et al. 2012), suggesting that the resource scavenging and storage functions of roots buffer these species against environmental variation (Heckathorn and Delucia 1994, Aerts and Chapin 2000), thereby promoting spatiotemporal stability in abundance (Chapin 1980, Tilman 1981, Tilman et al. 2006).

Given that $H_{\mathrm{N}}$ can be strongly correlated with species dominance and variation in abundance over the longterm, we assessed relationships between $H_{\mathrm{N}}$ and plant species responses to alterations in $\mathrm{N}$ availability in a nine-year $\mathrm{N}$-addition experiment. We expected that species with high $H_{\mathrm{N}}$ may be suppressed by increased $\mathrm{N}$ availability because of their inability to take advantage of this resource when abundant, as well as potential costs of maintaining a stable tissue stoichiometry in these environments (Sterner and Elser 2002, Sardans et al. 2012). In contrast, we predicted that those species with low $H_{\mathrm{N}}$ would respond to increased $\mathrm{N}$ with greater growth and increased abundances. Although there is abundant evidence that $\mathrm{N}$ deposition significantly impacts plant community composition over time (Xia and Wan 2008, Bai et al. 2010, Isbell et al. 2013, Borer et al. 2014), data are limited on how plant species with different $H$ values respond to chronic $\mathrm{N}$ additions.
A previous study showed that four years of $\mathrm{N}$ additions increased the abundance of plant species with low $H_{\mathrm{N}}$ and decreased the abundance of those with high $H_{\mathrm{N}}$ (Bai et al. 2010, Yu et al. 2010). However, in that relatively short-term $\mathrm{N}$-addition experiment, the relationship between $H_{\mathrm{N}}$ and species dominance did not change (Yu et al. 2010). Consistent with these results, during the first four years of $\mathrm{N}$ addition, we found that foliar $H_{\mathrm{N}}$ and species dominance were positively related for both the ambient and $\mathrm{N}$-addition treatments in two independent experiments, but this positive relationship weakened (became nonsignificant) after the fifth year of $\mathrm{N}$ addition. As observed previously, this reflects an overall change in abundances of grasses with long-term $\mathrm{N}$ addition in this grassland (Avolio et al. 2014). However, it is important to note that there was variation in responses of high $H_{\mathrm{N}}$ vs. low $H_{\mathrm{N}}$ grasses, as those that decreased or increased most were not the species with the highest or lowest $H_{\mathrm{N}}$. We found that dominance of S. scoparium, a grass species with the second highest $H_{\mathrm{N}}$ value, decreased significantly with $\mathrm{N}$ addition, with the dominance of the grass with the highest $H_{\mathrm{N}}$ value $(A$. gerardii) showing a similar, nonsignificant trend, while other grass species with lower $H_{\mathrm{N}}$ increased in abundance. These species-specific effects suggest that other 
mechanisms and traits beyond $H_{\mathrm{N}}$ may have influenced individual species responses to increased N. However, despite this variation, our results indicate $H_{\mathrm{N}}$ may be predictive of species responses (particularly those of grasses) to chronic $\mathrm{N}$ deposition, with high $H_{\mathrm{N}}$ species generally being suppressed and low $H_{\mathrm{N}}$ species being promoted.

Finally, we evaluated how well $H_{\mathrm{N}}$ could predict plant species responses to alterations in water availability, another soil resource commonly limiting plant growth and productivity in tallgrass prairie (Knapp et al. 2001, 2012). Water availability was altered within three experiments, two years of extreme drought (20102011), 14 years of altered precipitation variability (1998-2011), and 21 years of irrigation (1991-2011), which captured a range of forecast climate changes. Of these experiments, the extreme drought treatment imposed the most intense reduction in water availability and short-term water stress (Hoover et al. 2014), the altered precipitation variability treatment resulted in chronic but moderate reduction in soil moisture (Fay et al. 2011), and the irrigation treatment maintained soil water at nonlimiting levels for more than two decades (Knapp et al. 2012). We focused on responses of three species that were found in all three experiments and differed with respect to their $H_{\mathrm{N}}$ and their response to $\mathrm{N}$ addition. We found that the species with the highest $H_{\mathrm{N}}$ (A. gerardii) responded the least (was most stable) to either reductions or increases in soil water availability, while the species with the lowest $H_{\mathrm{N}}$ (S. canadensis) responded the most. These results correspond well with the finding that species with high $H_{\mathrm{N}}$ have higher temporal stability over the long-term (thereby encompassing variability in annual precipitation) both in the present study and in Inner Mongolia grasslands (Yu et al. 2010). Thus, with respect to climate change, our results suggest that species with high $H_{\mathrm{N}}$ may enhance ecosystem stability or resilience, whereas those with low $H_{\mathrm{N}}$ may be important for influencing ecosystem resistance to changes in climate (Hoover et al. 2014). Finally, the relationship between species dominance and $H_{\mathrm{N}}$ was not altered, and changes in water availability did not alter the relationship between soil and foliar $\mathrm{N}$ concentrations. These results indicate that the homeostatic relationship found for each species under a range of $\mathrm{N}$ availabilities did not change when another limiting resource in this system was altered.

In conclusion, we show that plant species with high $H_{\mathrm{N}}$ dominate and have high temporal stability in a $\mathrm{C}_{4}$ grassland, similar to previous studies in $\mathrm{C}_{3}$ grasslands (Yu et al. 2010, Dijkstra et al. 2012), and that this trait is strongly correlated with grassland plant responses to global changes that chronically alter resource availability. The links among stoichiometric homeostasis, species dominance and stability, and responses to short- and long-term changes in limiting soil resources suggests that $H$ for limiting resources may be reflective of a suite of traits (i.e., nutrient concentrations, shoot: root ratio, growth rate, nutrient use efficiency, water use efficiency; $\mathrm{Yu}$ et al. 2010) underlying strategies of resource acquisition and use. Although more research is needed to determine the generality of our findings and the mechanisms underlying the relationships we observed, this analysis provides a set of predictions for the relationship between $H$, plant success, and response to resource alterations ("the $H$ hypothesis"). First, we propose that plant species with high foliar $H$ for the most limiting soil nutrient in an ecosystem will dominate and have higher temporal stability in abundance. Second, long-term eutrophication should eventually suppress plant species with high foliar $H$ for the nutrient being altered (e.g., high $H_{\mathrm{N}}$ with $\mathrm{N}$ additions) while promoting low $H$ species for that nutrient. Third, species that tightly control their internal stoichiometry for soil nutrients also will be less sensitive to alterations in other soil resources, such as water, that are likely to be impacted by global change. We posit that the ability to acquire and store limiting nutrients (i.e., via an extensive root system) buffers the metabolism and growth of high $H$ species against variability in nutrients, as well as other co-varying soil resources such as water. This greater buffering capacity, in turn, promotes stability in abundance, particularly in the face of environmental variation in resources. While these appear to be potential mechanisms underlying success of plant species in U.S. and Asian grasslands, whether these predictions extend to other growth forms (shrubs or trees) or ecosystem types (deserts or forests) is unknown. However, if $H$ is a generalizable trait underlying species success and vulnerability to global environmental change, our ability to forecast future ecosystem structure and function will be enhanced.

\section{ACKNOWLEDGMENTS}

The authors thank Kelsey Duffy, Peter Bridgewater, and Qee Qee Gao for their assistance with this research. This work was supported by the Konza Prairie National Science Foundation Long Term Ecological Research Program, and the National Natural Science Foundation of China (41320104002).

\section{Literature Cited}

Aerts, R., and F. S. Chapin, III. 2000. The mineral nutrition of wild plants revisited: a re-evaluation of processes and patterns. Advances in Ecological Research 30:1-67.

Avolio, M. L., S. E. Koerner, K. J. La Pierre, K. R. Wilcox, G. W. T. Wilson, M. D. Smith, and S. L. Collins. 2014. Changes in plant community composition, not diversity, during a decade of nitrogen and phosphorus additions drive above-ground productivity in a tallgrass prairie. Journal of Ecology 102:1649-1660.

Bai, Y., J. Wu, C. M. Clark, S. Naeem, Q. Pan, J. Huang, L. Zhang, and X. Han. 2010. Tradeoffs and thresholds in the effects of nitrogen addition on biodiversity and ecosystem functioning: evidence from Inner Mongolia grasslands. Global Change Biology 16:358-372.

Bailey, A. W., and C. E. Poulton. 1968. Plant communities and environmental interrelationship in a portion of the Tillamook Burn, northwestern Oregon. Ecology 49:1-13.

Blair, J. M. 1997. Fire, N availability, and plant response in grasslands: a test of the transient maxima hypothesis. Ecology 78:2359-2368. 
Borer, E. T., et al. 2014. Herbivores and nutrients control grassland plant diversity via light limitation. Nature 508:517520.

Bremner, J. M. 1996. Nitrogen: total. Pages 1085-1123 in D. L. Sparks, A. L. Page, P. A. Loeppert, P. N. Soltanpour, M. A. Tabatabai, C. T. Johnston, and M. E. Sumner, editors. Methods of soil analysis part 3: chemical methods. Soil Science Society of America and American Society of Agronomy, Madison, Wisconsin, USA.

Chapin, F. S., III. 1980. The mineral nutrition of wild plants. Annual Review of Ecology and Systematics 11:233-260.

Daubenmire, R. 1952. Forest vegetation of northern Idaho and adjacent Washington, and its bearing on concepts of vegetation classification. Ecological Monographs 22:301330 .

Dijkstra, F. A., E. Pendall, J. A. Morgan, D. M. Blumenthal, Y. Carrillo, D. R. LeCain, R. F. Follett, and D. G. Williams. 2012. Climate change alters stoichiometry of phosphorus and nitrogen in a semiarid grassland. New Phytologist 196:807815.

Elser, J. J., M. E. S. Bracken, E. E. Cleland, D. S. Gruner, W. S. Harpole, H. Hillebrand, J. T. Ngai, E. W. Seabloom, J. B. Shurin, and J. E. Smith. 2007. Global analysis of nitrogen and phosphorus limitation of primary producers in freshwater, marine and terrestrial ecosystems. Ecology Letters 10: $1135-1142$.

Elser, J. J., W. F. Fagan, A. J. Kerkhoff, N. G. Swenson, and B. J. Enquist. 2010. Biological stoichiometry of plant production: metabolism, scaling and ecological response to global change. New Phytologist 186:593-608.

Fay, P. A., J. M. Blair, M. D. Smith, J. B. Nippert, J. D. Carlisle, and A. K. Knapp. 2011. Relative effects of precipitation variability and warming on tallgrass prairie ecosystem function. Biogeosciences 8:3053-3068.

Fay, P. A., J. D. Carlisle, A. K. Knapp, J. M. Blair, and S. L. Collins. 2000. Altering rainfall timing and quantity in a mesic grassland ecosystem: design and performance of rainfall manipulation shelters. Ecosystems 3:308-319.

Frost, P. C., M. A. Evans-White, Z. V. Finkel, T. C. Jensen, and V. Matzek. 2005. Are you what you eat? Physiological constraints on organismal stoichiometry in an elementally imbalanced world. Oikos 109:18-28.

Heckathorn, S. A., and E. H. Delucia. 1994. Drought-induced nitrogen retranslocation in perennial C-4 grasses of tallgrass prairie. Ecology 75:1877-1886.

Hessen, D. O., G. I. Ågren, T. R. Anderson, J. J. Elser, and P. C. de Ruiter. 2004. Carbon sequestration in ecosystems: the role of stoichiometry. Ecology 85:1179-1192.

Hoover, D. L., A. K. Knapp, and M. D. Smith. 2014. Resistance and resilience of a grassland ecosystem to climate extremes. Ecology 95:2646-2656.

Isbell, F., P. B. Reich, D. Tilman, S. E. Hobbie, S. Polasky, and S. Binder. 2013. Nutrient enrichment, biodiversity loss, and consequent declines in ecosystem productivity. Proceedings of the National Academy of Sciences USA 110:11911-11916.

Jeyasingh, P. D., L. J. Weider, and R. W. Sterner. 2009. Genetically-based trade-offs in response to stoichiometric food quality influence competition in a keystone aquatic herbivore. Ecology Letters 12:1229-1237.

Johnson, N. C., D. L. Rowland, L. Corkidi, and E. B. Allen. 2008. Plant winners and losers during grassland N-eutrophication differ in biomass allocation and mycorrhizas. Ecology 89:2868-2878.
Knapp, A. K., et al. 2008. Consequences of more extreme precipitation regimes for terrestrial ecosystems. Bioscience 58:811-821.

Knapp, A. K., J. M. Briggs, D. C. Hartnett, and S. L. Collins, editors. 1998. Grassland dynamics: long-term ecological research in tallgrass prairie. Oxford University Press, New York, New York, USA.

Knapp, A. K., J. M. Briggs, and J. K. Koelliker. 2001. Frequency and extent of water limitation to primary production in a mesic temperate grassland. Ecosystems 4: $19-28$.

Knapp, A. K., J. M. Briggs, and M. D. Smith. 2012. Community stability does not preclude ecosystem sensitivity to chronic resource alteration. Functional Ecology 26:12311233.

Kuo, S. 1996. Phosphrous. Pages 869-920 in D. L. Sparks, A. L. Page, P. A. Loeppert, P. N. Soltanpour, M. A. Tabatabai, C. T. Johnston, and M. E. Sumner, editors. Methods of soil analysis part 3: chemical methods. Soil Science Society of America and American Society of Agronomy, Madison, Wisconsin, USA.

Lambers, H., and H. Poorter. 1992. Inherent variation in growth-rate between higher-plants: a search for physiological causes and ecological consequences. Advances in Ecological Research 23:187-261.

Mehlich, A. 1984. Mehlich-3 soil test extractant-a modification of mehlich-2 extractant. Communications in Soil Science and Plant Analysis 15:1409-1416.

R Development Core Team. 2007. R: a language and environment for statistical computing. R Foundation for Statistical Computing, Vienna, Austria. www.r-project.org

Sardans, J., A. Rivas-Ubach, and J. Peñuelas. 2012. The C:N:P stoichiometry of organisms and ecosystems in a changing world: a review and perspectives. Perspectives in Plant Ecology, Evolution and Systematics 14:33-47.

Smith, M. D., A. K. Knapp, and S. L. Collins. 2009. A framework for assessing ecosystem dynamics in response to chronic resource alterations induced by global change. Ecology 90:3279-3289.

Sterner, R. W., and J. J. Elser. 2002. Ecological stoichiometry: the biology of elements from moleculaes to the biosphere. Princeton University Press, Princeton, New Jersey, USA.

Tilman, D. 1981. Resource competition and community structure. Monographs in Population Biology 17:1-296.

Tilman, D., P. B. Reich, and J. M. H. Knops. 2006. Biodiversity and ecosystem stability in a decade-long grassland experiment. Nature 441:629-632.

Wang, C. H., S. Q. Wan, X. R. Xing, L. Zhang, and X. G. Han. 2006. Temperature and soil moisture interactively affected soil net $\mathrm{N}$ mineralization in temperate grassland in Northern China. Soil Biology and Biochemistry 38:1101-1110.

Xia, J., and S. Wan. 2008. Global response patterns of terrestrial plant species to nitrogen addition. New Phytologist 179:428-439.

Yu, Q., Q. Chen, J. J. Elser, N. He, H. Wu, G. Zhang, J. Wu, Y. Bai, and X. Han. 2010. Linking stoichiometric homoeostasis with ecosystem structure, functioning and stability. Ecology Letters 13:1390-1399.

Yu, Q., J. Elser, N. He, H. Wu, Q. Chen, G. Zhang, and X. Han. 2011. Stoichiometric homeostasis of vascular plants in the Inner Mongolia grassland. Oecologia 166:1-10.

Yu, Q., H. Wu, N. He, X. Lü, Z. Wang, J. J. Elser, J. Wu, and X. Han. 2012. Testing the growth rate hypothesis in vascular plants with above- and below-ground biomass. PLoS ONE 7: e32162.

\section{Supplemental Material}

